We describe a case of Haemoglobin Sun Prairie, a rare form of alpha thalassemia, caused by an unstable alpha-2-globin variant created by a point mutation in the gene coding for the globulin structure at codon 130, resulting in an alanine to proline switch. This results in an haemolytic anaemia; characterised by a low mean corpuscular volume, small mean corpuscular haemoglobin but relatively normal mean corpuscular haemoglobin concentration. This 25 year old lady is one of only a small number of people in the world with the condition, and this case report is the first reported case during pregnancy. Fertility is not an issue; her main symptoms being those of anaemia and gross haemaglobinuria, for which she was blood transfusion dependent. Potential pregnancy related complications include premature labour, intrauterine growth restriction and pre-eclampsia. Serial fetal growth scans were undertaken revealing a growth velocity within normal limits and her haemoglobin was maintained at approximately $9 \mathrm{~g} / \mathrm{dl}$, however, at 39 weeks gestation pregnancy induced hypertension developed. This necessitated induction of labour which subsequently resulted in delivery by emergency Caesarean section for presumed fetal distress. The baby had normal cord gases and good APGAR scores. This lady has gone on to have 2 further pregnancies with the delivery of 2 healthy babies. This case report illustrates that when managed appropriately, with close surveillance in a joint obstetric and haematology clinic, with serial fetal growth scans and blood transfusions as and when required, the outcome for both mother and baby are good.

\section{PM.49 REPRODUCTIVE LOSS FROM A MULTIPLE PREGNANCY: HEALTH PROFESSIONALS' PERSPECTIVES}

doi:10.1136/archdischild-2013-303966.131

1J Richards, ${ }^{2} \mathrm{R}$ Graham, ${ }^{3} \mathrm{~N}$ Embleton, ${ }^{4} \mathrm{~S}$ Robson, ${ }^{1} \mathrm{~J}$ Rankin. ${ }^{1}$ Insitute of Health \& Society, Newcastle Upon-Tyne, UK; ${ }^{2}$ School of Geography, Politics and Sociology., Newcastle Upon-Tyne, UK; ${ }^{3}$ Royal Victoria Infirmary, Newcastle Upon-Tyne, UK; ${ }^{4}$ nstitute of Cellular Medicine, Newcastle Upon-Tyne, UK

Objective To provide an in-depth understanding of the experiences of health professionals who care for parents who have had a loss from a multiple pregnancy.

Method A qualitative study involving semi -structured interviews. Participants were recruited from two NHS Tertiary hospital units: a Critical Care Baby Ward and Fetal Medicine department. 26 health professionals from a range of clinical roles were interviewed. Data were analysed using a generative thematic approach.

Results Whilst all health professionals felt confident in administering medical care, they felt less confident when dealing with the bereavement issues of parents who may spend many months in hospital whilst surviving multiples are cared for. Staff often felt that they were 'second guessing' what parents' needs might be and feared 'saying the wrong thing' within daily interactions with parents.

Conclusion Many staff, particularly those in more junior roles, felt that they would benefit from formal bereavement training in order to understand more fully how to react effectively to parents' emotional needs. Staff also felt they lacked information regarding the formal bereavement services available to parents and were unsure as to when it was appropriate to utilise them. The value of experience was also acknowledged however, alongside the need for flexibility of approach in order to react to the specific needs of parents.

\section{PM.50 MATERNITY SERVICES IN THE IRISH MASS MEDIA: AN ANALYSIS OF MEDIA CONTENT FROM 2007-2012}

doi:10.1136/archdischild-2013-303966.132

${ }^{1}$ A Marron, ${ }^{2} \mathrm{G}$ Burke, ${ }^{3} \mathrm{E}$ Devereux, ${ }^{4} \mathrm{M}$ Breen. ${ }^{1}$ University of Limerick, Limerick, Ireland,

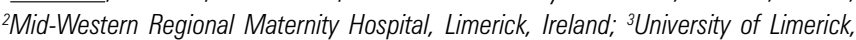
Limerick, Ireland; ${ }^{4}$ Mary Immaculate College, Limerick, Ireland
The mass media play a key role in informing the public about matters of public interest and, critically, in the actual shaping of public opinion about those matters. With this in mind, the purpose of this study was to examine Irish media content and the manner in which it portrays the maternity services in Ireland.

A quantitative content analysis was conducted over the five-year time period from 2007 to 2012. Using the Nexis-Lexis newspaper database, data were sampled from three broadsheet newspapers (the Irish Times, the Irish Independent and the Irish Examiner), one tabloid newspaper (the Irish Daily Mail) and the RTE website. Articles were measured according to a pre-defined coding scheme that included variables such as article placement, storey length, topic, etc. and they were then compared against existing medical statistics.

The results showed that less than $1 \%$ of articles relating to the Irish maternity services received front page treatment over the fiveyear period. Medico-legal processes (18.8\%), budgetary and staffing issues $(15.8 \%)$ and specific high-profile cases of misdiagnosis or inappropriate treatment $(9.7 \%)$ have predominated as the focus of coverage. The more clinical matters, such as breastfeeding $(4.5 \%)$, neonatal care (3.3\%) and post-natal depression (1.2\%), have received relatively little examination.

The need for the public to have access to accurate information about medical matters is clearly of fundamental importance. However, the findings of this research suggest that there is a discrepancy between media representations of these critical issues and the medical realities, which has the potential to undermine public perception.

\section{PM.51 CHALLENGES OF MANAGING PREGNANCY COMPLICATED BY CHRONIC KIDNEY DISEASE STAGES 3-5: A TERTIARY CENTRE'S EXPERIENCE}

doi:10.1136/archdischild-2013-303966.133

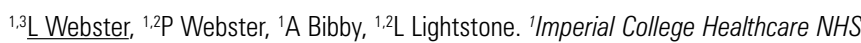
Trust, London, UK; '2Imperial College University, London, UK; ${ }^{3 K i n g}$ 's College Universtiy, London, UK

Objectives Establish the obstetric and neonatal outcomes in women with chronic kidney disease (CKD) stages 3-5 attending renal antenatal clinic from 1999 to present.

Methods All women with excretory renal dysfunction (creatinine $>110 \mu \mathrm{mol} / \mathrm{L}$ or eGFR $<60 \mathrm{ml} / \mathrm{min}$ ) prior to their pregnancy were identified from the Obstetric-Renal database. Outcomes assessed were: small for gestational age (SGA) infants $\left(<10^{\text {th }}\right.$ centile) calculated using the GROW ${ }^{1}$ formula, prematurity (both $<37$ and $<34$ weeks), pre-eclampsia and mode of delivery.

Results 67 pregnancies in 55 women complicated by CKD 3-5 were identified. Three twin pregnancies were excluded from the analysis to prevent confounding of multiple gestation. Sufficient data to calculate birth centile was absent for 21 pregnancies. GROW birth centile was therefore calculated in 43 pregnancies, 14 $(33 \%)$ were below the $10^{\text {th }}$ centile and $25(58 \%)$ were below the $25^{\text {th }}$ centile.

Analysis of all 64 pregnancies revealed 19 babies (30\%) were delivered before 34 weeks and 36 (56\%) were delivered before 37 weeks. All women were delivered before 40 completed weeks. There was one stillbirth at 28 weeks and one neonatal death of a baby born at 31 weeks. 31 (48\%) babies required admission to the neonatal unit. Twelve (19\%) pregnancies were complicated by preeclampsia.

In $8(12 \%)$ pregnancies spontaneous labour occurred and in 24 (38\%) labour was induced. The other $32(50 \%)$ were planned caesarean sections and the total caesarean section rate was $66 \%$.

Conclusions Pregnancies complicated by CKD stages 3-5 are obstetrically high risk and women should enter pregnancy aware of the possible complications. 